\title{
Effect of Plant Growth Regulators (IBA \& NAA) on Propagation of Guava (Pisidium guajava L.) by Cutting - A Review
}

\author{
Tanishka Thapa ${ }^{1}$ and Vijaya Rawat $^{2 *}$ \\ ${ }^{1}$ Department of Horticulture, SAGR, Lovely Professional University, Punjab, India \\ ${ }^{2}$ School of Agriculture, Lovely Professional University, Punjab, India \\ *Corresponding author
}

A B S T R A C T

\section{Keywords}

Layering, Stooling, Cutting, Grafting, IBA (Indole-3butyric acid), NAA (Napthalene acetic acid

\section{Article Info}

Accepted:

04 October 2020

Available Online:

10 November 2020
Guava can be propagated through seeds and vegetative methods like Layering, Stooling, Cutting and Grafting. Propagation through cuttings was not a standard method that was followed for propagation of Guava but it has now gained popularity since it results in desired true-to type plants in a smaller period of plantation. Cuttings are mainly propagated under misted conditions by the applying plant growth regulators especially auxins such as IBA and NAA to induce rooting. This review concentrates on analyzing the recommended concentration along with the combination of plant growth regulators for maximum survival and rooting in different stem cuttings of Guava.

\section{Introduction}

Guava (Psidium guajava L.) is a delicious fruit that belongs to Myrtaceae family. Its basic chromosome number $x=11$ and $2 n=22$. It is a hardy plant and is considered as an ideal fruit for nutritional security. It has been culture from ancient period and is commonly known as "Poor man's apple" (Qadri et al., 2018). Guava is originally from Tropical America and is cultivated throughout the subtropical and tropical regions of India like Uttar Pradesh, Gujrat, Punjab, Madhya Pradesh, Andhra Pradesh, Tamil Nadu, West Bengal, Maharashtra, Karnataka etc. It is the fourth most important fruit crop in area as well as production after Mango, Banana and Citrus. It is also called as the 'Apple of the Tropics' and contains high vitamin $\mathrm{C}$, mineral content and pectin. The pulp contains vary number and hardness of seeds and it is off white to deep pink depending on the variety.

Guava is a prolific bearer with high ascorbic acid content. Guava can be used for the treatment of dysentery, hypertension, diabetes etc. (Naseer et al., 2018). It also has wide adaptability, potential of fruiting all year round and it can withstand drought condition. Over all Guava is a hardy plant but the young 
plants are susceptible to severe frost that can result in mortality. Guava is propagated through sexual method as well as vegetative methods of propagation. Though guava can be successfully propagated by seeds but the vegetative methods of propagation are preferred as through seedling propagation genetic purity cannot be maintained since it can result in genetical variations which can affect the fruit quality, shape size and yield. And seedling plants take 6-7 years to come into bearing stage therefore they are used to raise rootstocks for budding and grafting. There are many methods of vegetative propagation in Guava like layering, cutting, grafting, stooling and budding.

Propagation by cuttings can either be done by root cutting or shoot cutting. But root cuttings are not as popular as stem cuttings. Since, propagation by root cutting can only be done from parent plants that have been started from cuttings (Shiguera et al.,). Stem cutting is a vegetative method of propagation in which a piece of stem with at least three nodes and internodes are used for propagation. As per the length of internode, the length of the cutting is decreased to ensure at least one node remains inside the soil (Pereira et al., 2017). The cuttings should be from a healthy plant and should be flexible. The cuttings have to be treated with plant growth regulators to promote rooting.

Plant growth regulators are synthetic substances which produce identical results like natural plant hormones which are synthesized in the plants in a very small amount. They are also known as 'Phytohormones'. Plant Growth Regulators are used in agricultural and horticultural technology to stimulate the developmental processes of the plants. They can be used for various purposes like germination, vegetative and reproductive development, senescence etc. There are mainly five categories of plant growth regulators: Auxin, Cytokinin, Gibberellin, Ethylene and Abscisic acid. Auxin was the first discovered by Fritz W. Went in 1928 from the tip of coleoptile of Oat. The commonly occurring auxin in most plants is Indole-3-acetic acid (IAA) (Davies, 2012). The functions of auxin consists of cell enlargement, vascular tissue differentiation, flowering, root initiation etc.The most popularly used plant growth regulator for rooting in cuttings is Auxin.

The auxins used for propagation through cuttings are Indole -3-butyric acid (IBA) or Naphthalene acetic acid (NAA). Suitable temperature $\left(28-30^{\circ} \mathrm{C}\right)$ and relative humidity (70-80\%) should be provided to the cuttings to ensure proper rooting and survival. Therefore, for rapid propagation of any cuttings a controlled environment of green houses or any other sheltered areas is necessary. Though Guava is hard to root the application of Auxin has indicated positive results in root initiation in stem cutting. Plant growth regulators (auxin) are used to induce adventitious root formation in stem cuttings of Guava.

Yasir Ali, 2018 conducted an experiment on cuttings of Guava by using different concentration of IBA to record the response. It was observed that IBA @ 2000 ppm had higher survival rate and IBA @ 4000 ppm had higher rooting percentage in guava stem cuttings.

Rani et al., 2018 conducted a study on the effect of IBA (Indole-3-butyric acid) treatment on the terminal cuttings of Guava cv. Taiwan Pink. It was reported that the best results were found in the treatment of IBA @ $3000 \mathrm{ppm}$ in rooting percentage, dry weight of shoots, number of leaves, leaf area, leaf chlorophyll content and the survival rate of the cuttings. 
The cuttings are dipped in the growth regulator (Auxin) and then planted in plastic bags or pots with soil mixture. After an appropriate period of time when the cuttings are matured enough they are transplanted to the field. Adequate amount of watering, temperature and humidity with careful handling result in successful cuttings. Though cutting was not a popular method in the olden days for guava propagation. Since Guava can be difficult to root unless it is supported by plant growth hormones and adequate conditions (Belachew, 2011). But now due to rise of various technologies it is a great method to procure rapid and high quality true to types plants. Cuttings are also helpful in obtaining desired amount of vigorous plants in a shorter period of time. Therefore cuttings can result as a more efficient method of propagation of Guava.

\section{Effect of plant growth regulators on different guava cuttings}

Plant growth regulators have known to be used for enhancement in propagation of plant especially in cutting. Therefore, during the propagation of Guava through cutting plant growth regulators like auxins are used. The most common plant growth regulator or auxin used is Indole-3-butyric acid (IBA) or Napthalene acetic acid (NAA) to stimulate rooting in cuttings. There are three types of cuttings that ae used for propagationSoftwood cutting, Semi-hardwood cutting and Hardwood cutting. (Rahman et al., 2004) researched on 3 different types plant growth regulators paclobutrazol, IBA and NAA @ 1000 ppm each and applied it on Semihardwood, Hardwood and Softwood cuttings of Guava. He observed maximum amount of roots (59.66) and shoot length $(8.24 \mathrm{~cm})$ when treatment of IBA @ 1000 ppm was applied on softwood cuttings and days of sprout (17.68) and highest root length $(12.81 \mathrm{~cm})$ when treated with NAA @ 1000 ppm. The highest survival percentage (57.22\%) was recorded when paclobutrazol treatment was given to the softwood cutting.

Ullah et al., (2005) conducted a study on various types of cuttings of guava and observed that the highest number of roots (59.66) along with maximum shoot length $(8.24 \mathrm{~cm})$ was recorded in the softwood cuttings of Guava applied with IBA@ 1000ppm. Maximum root size along with days to early sprout (17.68 days) was also recorded in the softwood and semi hardwood cuttings respectively treated with NAA@ 1000ppm.

Though best performance of plant growth regulators has been observed in high concentrations. (Khan et al., 2016) recorded that IBA@ 4000 ppm showed early sprouting (22.0) and maximum sprouting percent (68.22\%), average root length (31.65), sprouted cuttings (40.11), and survival percent $(57.82 \%)$ average number of roots per cutting (31.65) respectively.

(Soni et al., 2016) observed hardwood and semi-hardwood cuttings of guava in different rooting media in the net house environment. It was recorded that high survival percentage (33.09 and 36.63\%) in hardwood and semihardwood was reported in cuttings treated with IBA @ 3000ppm. The stem cuttings dipped in IBA @ 3000ppm showed maximum length of shoots $7.76 \mathrm{~cm}$ in softwood cuttings and $10.91 \mathrm{~cm}$ shoot length in semi-hard wood cuttings. It was concluded that the plants produced by this technique will be true-totype and can be used for high density plantation.

Prakash et al., (2018) did a study on effect of plant growth regulators on different types of cuttings (softwood, semi hardwood and hardwood cuttings) of guava. Significantly higher sprouting percentage (76.66\%) and 
rooting percentage $(74.44 \%)$ with early sprouting (19.10 days) was observed IBA treatment @ 4000 ppm on softwood cuttings. The maximum amount of leaves (25.80) after 90 days of planting was observed in the hardwood cuttings treated with IBA@ 4000 ppm. Softwood cuttings showed best results in rooting and sprouting performance when treated with IBA@ 4000 ppm among the three stem cuttings.

\section{Effect of combination of plant growth regulators on guava cuttings}

Combination of plant growth regulators have also been used for further improvement in the performance of the Guava cuttings. (Shahzad et al., 2019) did an experiment on softwood cuttings of Guava and observed the top outcome as per the total number of leaves and roots per cutting, number of days to sprout, length of root in soil + peat moss + sand + bagasse as well as peat moss + soil media by using the combination of IBA $1600 \mathrm{ppm}+$ NAA 7000 ppm.

(Al-Obeed et al., 2000) used 15 treatments including IBA and NAA both and alone with catechol and cinnamic acid. He observed highest percentage of rooting $(62.9 \%)$ in cutting when treated with IBA + Catechol @ $1000 \mathrm{ppm}$ and cuttings treated with NAA + Catechol@ 1000 ppm (59.6\%). Use of combinations of plant growth regulators has shown some favorable results. With more research the right combination and optimum concentration can be obtained which then can be used to further enhance the propagation of Guava cuttings.

Wahab et al., (2001) conducted a study on IAA, IBA and NAA at different concentrations i.e. 0, 1000, 2000, 3000, 4000, 5000 or $6000 \mathrm{ppm}$ on the semi-hardwood cuttings of guava. The highest survival percentage (12.50) was observed in cuttings that were treated with IAA @ 3000 and $6000 \mathrm{ppm} \& \mathrm{NAA}+\mathrm{IBA}$ both @ 6000 ppm. The maximum amount of roots (23.75) was reported in cuttings that were treated with IBA@ 4000ppm and highest sprouting was recorded in IBA @ 3000 (79.84\%), IBA @ $1000 \operatorname{ppm}(75.96 \%)$ and NAA @ 2000 ppm $76.59 \%$ respectively.

Similar research and study has been done on other crops. (Henrique et al., 2006) conducted an experiment on cuttings of Pinus caribae var. hondurensis by treating them with combination of concentrations of NAA (Naphthalene acetic acid), IBA (Indole butyric acid) and PBZ (Paclobutrazol). It was reported that the effect of IBA on the root initiation of the cuttings was higher as compared to NAA. The highest rooting percentage was observed in the treatment of IBA @ 4000mg/L + Palobutrazol @ $100 \mathrm{mg} / \mathrm{L}$.

(Dahale et al., 2018) did an experiment on the effect of IBA and NAA treatments on the hard wood cuttings of Fig cv. Dinakar. Ten different treatments were used among which the treatment of IBA@1000ppm + NAA @ $1000 \mathrm{ppm}$ resulted in higher shoot growth, root growth, rooting percentage, survival percentage $(82.50 \%)$ and root to shoot ratio. It was also recorded that the same treatment resulted in higher induction of rooting $(58.66 \%)$.

(Patil et al., 2001) conducted a study on methods to improve growth and survival of hard wood cuttings in grape cv. Tas-e-Ganesh and Kismischorny by the application of plant growth regulators (IBA and NAA). It was reported that IBA + NAA resulted in higher survival rate and shoot growth. It was observed that the effect of IBA @ 100ppm and NAA ppm was significantly higher as compared to control but caused decreased survival rate. 
Successful cuttings can be obtained by the use of different plant growth regulators therefore it is to be assumed that successful result can also be obtained with the use of combination of these different plant growth regulators. Though more research and study is needed as evidence to prove the synergistic effect of plant growth regulators on guava cuttings, which might result in a significant change in the propagation methods of Guava through cuttings.

In conclusion the paper is to establish the potential of the utilization of plant growth regulators in improving the overall performance and development of the propagation of Guava cuttings. Since the use of auxin has been known to increase rooting and the survival percentage of guava cuttings. Therefore the guava plants can be established successfully by the use of plant growth regulators. But refinement is necessary in the technology for proper application. But the efficient utilization of the plant growth regulators can actually help in the establishment of cuttings as a commercial method of propagation of Guava thus leading to a drastic change in its propagation. The use of the optimum concentration and the combination of plant growth regulators can help to improve propagation in guava cuttings by reduction in time period as well as overall cost.

\section{References}

Ahmad, M.Ahmad and I. Laghari (1998) Effect of growth regulators on rooting in softwood cuttings of guava under mist condition. Sarhad Journal of Agriculture (Pakistan) Vol. 15 :42-425.

Amarjit Basra (2000) Plant growth regulators in agriculture and horticulture : their role and commercial uses.

Andréia Henrique, Duardo Nogueira Campinhos, Elizabeth Orika Ono and
Sheila Zambello de Pinho (2006) Effect of plant growth regulators in the rooting of pinus cuttings. Brazilian Archives of Biology and Technology Volume 49 No. $2: 189-196$.

Jarvis, B. C. and S. Yasmin (1987) Plant growth regulators and adventitious root development in relation to auxin. Biologia P lantarum Volume 29: 189198.

Dera Ghazi Khan (2016) Effect of different concentrations of IBA on rooting of guava (Psidium guajava L.) in low tunnel under shady situation. Journal of Agriculture and Environment for International Development 110(2): 197-203.

FazliWahab, GhulhamNabi, Nawab Ali and Muslim Shah (2001) Rooting response of semi-hardwood cuttings of guava (Psidium guajava L.) to various concentrations of different auxins. Journal of Biological,1: 184-187.

Fernando Mendes Pereira, Muhammad Usman, Newton Alex Mayer, Jair Costa Nachtigal, Oscar Ranny Mbongeni Maphanga and Salomie Willemse (2017) Advances in guava propagation. Revisita Brasileira de Fruticultura, Vol. 39, No. 4, e-358.

George D. Ruehle (1948) A rapid method of propagating the guava international tropical fruits network, guava. Introduction Agronomy National Horticulture Board-Guava, Alifornia Avocado Society, Yearbook 33:108112.

KiflemariamYehuala Belachew (2011) Rooting of guava (Psidium guajava L.) shoots and stem cuttings. Lambert Academic Publishing Gmb H \& Co. KG.

Krishan Kumar Singh (2018) A review : macro-propagation of guava (Psidium guajava). Journal of Pharmacosgnosy and Phytochemistry Volume 7(2) : 
2629-2634.

Megha Dahal, Ekta P. Ningot and N. MuskeDeepa (2018) Effect of plant growth regulators on rooting and survival of hard wood cuttings in fig. International Journal of Current Microbiology and Applied Sciences Special Issue 6: 2386-2391.

Nickell, L. M. (1982) Plant growth regulatorsagricultural uses.

Siva Prakash, M., J. Rajangam, V. Swaminathan and K. Venkatesan (2018) Effect of plant growth regulators on rooting and sprouting of different stem cuttings of guava (Psidiumguajava L.) cv. Lucknow-49 under mist chamber condition. Madras Agricultural Journal, Vol. 105 : pp336340.

Nitin Soni, S.K. pandey, S.S. Singh, S.R.K. Singh, A. Mishra, S.S. Baghel and Pavan. Kumar Kaurav (2016) Propagation of guava through cuttage under net house condition at Jabalpur Madhya Pradesh, India. Flora and Fauna Vol.22 No. 1: pp 36-40.

Noor Rahman, Tehsimullah, Ghulam Nabi and Taslim Jan (2004) Effect of different growth-regulators and types of cuttings on rooting of guava. Quarterly Science Vision Vol.9 : 1-5.

Peter J. Davis (2012) The plant hormones : their nature, occurrence, and functions.

Rashad Qadri, Muhammad Azam. Shan Bakhtawar Khan, Imran Khan, Imran Ulhaq, Yaodong Yang, M. Muzammil J, M. awais Ghani and M. Mozzam (2018) Growth performance of guava cutting under different growing media and plant cutting taking height. Bulgarian Journal of Agricultural Science, 24(No 2) : 236-243.

R.S Al-Obeed (2000) The effect of growth regulators, phenolic compounds and time of propagation on the rooting of guava stem cuttings. Journal of
Forestry Research, Vol 17, 301-304.

S. G. Gollagi, G. K. Ravi. G. L. Veeena and B. M. Muralihara (2019) Role of plant growth regulators in guava (Psidium guajava L.) cultivation: A review. Journal of Pharmacognosy and Phtyochemistry 8(3): 805-808.

Shiguera, G.T. and R.M. Bullock - Crop knowledge master (Guava).

SumraNaseer, Shabbir Hussain, NaureenNaeem, Muhammad Pervaiz and Madiha Rahman (2018) Thephytochemistry and medicinal value of Psidium guajava (Guava). Clinical Phytoscience Volume 4(32) :18.

TahseenUllah, FaridUllah Wazir, Masood Ahmad, FarhadAnaloui, MohibUllah Khan and Masood Ahmad (2005) A Break Through in Guava (Psidium guajava L.) Propagation from cutting. Asian Journal of Plant Sciences 4(3): 238-243.

T. Dhatrika Rani, D. Srihari, A. V. D. Dorajeerao and P. Subbaramamma (2018) Effect of rooting media and IBA treatments on shoot production ad survival of terminal cutting in guava (Psidium guajava L.) cv. taiwan pink. International Journal of Current Microbiology and Applied Sciences Volume 7(11) : 231-242.

Umbreen Shahzad, Abul Kareem, Khadija Altaf, Shah Zaman, QudsiaYousafi and Phoebe Calica (2019) Effect of auxin and media additives on the clonal propagation of guava cuttings (Psidium guajava L.) var. chinesegola. Journal of Agriculture Science and Food Resources, Volume 10 : 1-4.

V. N. Patil, P. S. Chauhan, R. S. Shivankar, S. H. Vilhekar and V. S. Waghmare (2001) Effect of plant growth regulators on survival and vegetative growth of grapevine cuttings. Agricultural Science Digest Volume 
21, Issue 2 : 97-99.

Yasir Ali (2018) Rooting and survival percentage in Guava (Psidium guajava L.) cuttings and its response to different IBA concentrations. International Journal of Advanced Research and
Review 3(1): 55-58.

Yunde Zhao. (2010). Auxin biosynthesis and its role in plant development. Annual Review of Plant Biology Volume 61 : 49-64.

\section{How to cite this article:}

Tanishka Thapa and Vijaya Rawat. 2020. Effect of Plant Growth Regulators (IBA \& NAA) on Propagation of Guava (Pisidium guajava L.) by Cutting - A Review. Int.J.Curr.Microbiol.App.Sci. 9(11): 278-284. doi: https://doi.org/10.20546/ijcmas.2020.911.033 